\title{
The burden of serious ocular injury
}

The occurrence of ocular trauma is a facet of everyday life and prevalent in all societies. Within community surveys, ocular trauma continues to rank among the leading causes of uniocular visual impairment. ${ }^{1}$ The majority of injuries, however, are superficial in nature and transient in their effects but nevertheless place considerable demands on our accident and emergency services. ${ }^{2}$ Serious ocular injury on the other hand, by definition, gives rise to irrevocable structural damage or functional loss. For the afflicted individual, this can impose an enduring burden often throughout the most productive years of life. Although difficult to quantify, the overall cost to society and the drain upon health resources are considerable. ${ }^{3}$ In common with all accidental injuries, the causes of ocular injury relate to the environmental hazards of the day and on occasions reflect some of the worst ills in society as witness the victims of malicious assault. ${ }^{4-6} \mathrm{~A}$ greater number of severe injuries now occur during leisure time and including sporting activities. Inevitably, new hazards constantly arise and require continued vigilance. Although the circumstances of injury often appear fortuitous, a high proportion of all trauma is predictable and hence avoidable. Clearly much depends on the awareness of risk and the use of appropriate safety measures, although compliance even in high risk groups often leaves much to be desired.

The availability of current epidemiological data is indispensable if we are to identify the prevailing causes and patterns of serious ocular injury and above all to devise effective strategies for their prevention. A number of reports published over the past decade contribute to our understanding of the problem and to the recognition of ocular trauma as a significant public health issue. ${ }^{8}$

Many of these reports, however, deal with specific categories of injury, or are confined to particular locations or selected age groups. ${ }^{9-12}$ Data sources for these studies include telephone questionnaires, hospital attendances and admissions, as well as routine statistical returns. Some rely upon retrospective data while others are derived from the voluntary reporting systems within national eye trauma registries. Prospective population based studies undertaken in the UK and elsewhere are by contrast few in number but provide estimates of the incidence or prevalence of ocular injury. In this issue of the $B \mathcal{F}$ (p 592) the report of Desai et al contains important and highly pertinent data on the incidence and outcome of serious injury derived from the Scottish Ocular Trauma Survey (SCOTS). Analysis of this survey based upon hospital admissions within a defined population provides a direct estimate of visual impairment attributable to serious ocular injury, an outcome measure which hitherto has not been reported: $13.2 \%$ of patients suffered significant impairment of vision and in $5 \%$ the ultimate visual outcome was no light perception. The reported 1 year cumulative incidence of serious ocular trauma bears remarkable similarity to the estimates reported by Morris et al in $1987^{13}$ and by Canavan et al 20 years ago. ${ }^{14}$ The home was found to be the most frequent location for moderate or severe ocular injury irrespective of age, a finding which broadly concurs with previous studies. ${ }^{15}$ As reported elsewhere, ${ }^{16}$ assault was responsible for approximately one fifth of all injuries whereas road traffic accidents accounted for only $3.4 \%$.
The report also identifies the high loss to follow up so often encountered in trauma studies and the shortcomings associated with routine hospital activity returns. As the authors point out, extrapolation of these data to include the entire population of the UK would indicate at least 5000 patients annually sustain serious injury sufficient to require hospital admission.

The invaluable data available from this report and other surveys offer a mere snapshot of the problem. In the absence of a formal surveillance scheme we have little or no means of determining the rise or fall in the incidence of serious injury or judging the effectiveness of preventive strategies. It may be said that one of the great benefits of a national health service is the opportunity to acquire reliable nationwide data and the establishment of a UK eye trauma registry through the hospital eye service is surely a goal worth pursuing and long overdue.

There is no reason to believe the burden of serious ocular injury has declined in the UK over the past two decades. The demographic characteristics of those most vulnerable to sight threatening injury are unchanged but in relative terms the predominant location has moved from the bustle of the workplace to the comfort of the home. Future efforts to reduce this burden should, therefore, as with all other accidental injuries focus upon the home environment. We should also note that Health of the Nation has identified the prevention of accidents as a national priority $^{17}$ and although directed towards avoidable mortality, the inclusion of avoidable visual impairment resulting from ocular injury within the national strategy for health is a just cause.

ROBERT J COOLING

Moorfields Eye Hospital,

City Road, London EC1V 2PD

1 Attebo K, Mitchell P, Smith W. Visual acuity and the causes of visual loss in Australia. Ophthalmology 1996;103:357-64.

2 MacEwen CJ. Eye injuries: a prospective survey of 5671 cases. $\mathrm{Br} f$ Ophthalmol 1989;73:888-94.

Tielsch JM, Parver LM. Determinants of hospital charges and length of stay for ocular trauma. Ophthalmology 1990;97:231-7.

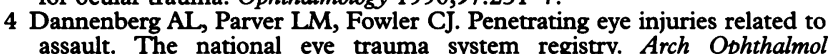
assault. The nation.

5 Groessl S, Nanda SK, Mieler WF. Assault-related penetrating ocular injury. Am f Ophthalmol 1993;116:26-33.

6 Shepherd JP, Farrington DP. Assault as a public health problem: discussion paper. $\mathcal{F}$ Roy Soc of Med 1993;86:89-92.

Liu C, Davison C, Cooling RJ. Eye protection in the metal working industry. $B M \Im$ 1990;301:1048.

8 Tielsch JM. Frequency and consequences of ocular trauma. A population perspective. Ophthalmol Clin N Am 1995;8:559-67.

9 LaRoche GR, McIntyre L, Schertzer RM. Epidemiology of severe eye injuries in childhood. Ophthalmology 1988;98:1603-7.

10 Liggett PE, Pince KJ, Barlow W, Ragen M, Ryan SJ. Ocular trauma in an urban population. Review of 1132 cases. Ophthalmology 1990;97:581-4.

Zagelbaum BM, Tostanoski JR, Kerner DJ, Hersh PS. Urban eye trauma. A one-year prospective study. Ophthalmology 1993;100:851-6.

12 Alfaro DV, Chaudhry NA, Walonker AF, Runyan T, Saito Y, Liggett PE. Penetrating eye injuries in young children. Retina 1994;14:201-5.

13 Morris RE, Witherspoon CD, Helms HA Jr. Eye injury registry of Alabama (preliminary report): demographics and prognosis of severe eye injury. South Med $\Im$ 1987;80:810-6.

14 Canavan YM, O'Flaherty MJ, Archer DB, Elwood JH. A 10-year survey of injuries in Northern Ireland 1967-76. Brf Ophthalmol 1980;64:618-25.

15 Koval RK, Teller J, Belkin M, Yanko L, Savir H. The Israeli Ocular Injuries Study. A nationwide collaborative study. Arch Ophthalmol 1988;106:77680.

16 Desai P, MacEwen CJ, Baines P, Minassian DC. Epidemiology and implications of ocular trauma admitted to hospital. I Epidemiol Community Hlth 1996;in press.

17 Department of Health. The health of the nation: a strategy for health in England. London: HMSO, 1992. 